Miranda Mas, Carlos.

Profesor Contratado Doctor, Universidad de Málaga, Departamento de Arte y Arquitectura.

\title{
Aperturas narrativas desde la interacción espacial entre cómic y pintura.
}

\section{Narrative openings from the spatial interaction between comic and painting.}

\author{
TIPO DE TRABAJO: \\ Comunicación. \\ PALABRAS CLAVE: \\ Heterocronía, Multitemporalidad, Pintura, Cómic, Instalación.
}

KEY WORDS:

Heterocrony, Multitemporality, Painting, Comic, Installation.

RESUMEN.

La presente comunicación viene a mostrar un proyecto artístico basado en reconfigurar, cruzándolos, dos tipos de códigos, uno propio del consumo de masas como es el cómic, y otro de la recepción especializada y presencial como es el de la pintura. Asimismo, la temática que, como veremos, es objeto de narrativización mediante la citada confluencia disciplinar, retrotrae el resultado de difusión pública del trabajo intelectual al contexto de sus condiciones procesuales puramente domésticas. Por tanto, a través de la conjugación interesada de las citadas disciplinas produzco una suerte de narraciones espaciales que vienen a modificar los modos de recepción de los objetos culturales a que se refieren (novelas, exposiciones, artículos, ensayos, etc.). Para ello, se ha desarrollado todo un programa de trabajo que profundiza en las posibilidades de la representación pictórica para generar metarrelatos, produciendo una serie de instalaciones que, sobre la base de transformar el espacio expositivo en una infinita sucesión de grandes viñetas, integran cuadros que atienden a la caracterización gráfica y argumental del desorden propio de las prácticas íntimas de habitación durante el trabajo, que viene a ser reveladora de unos asentamientos en el territorio doméstico dados por su condición de espacios para crear historias, pues todos ellos son lugares de vida y labor de distintos narradores profesionales. Cada cuadro-viñeta, pues, es titulado con el de la ficha descriptiva de obra que estaba realizando cada uno de tales autores al recibir la visita -cámara en mano- de quien suscribe, a partir de cuyas fotografías se han compuesto las pinturas, narraciones de segundo grado que vienen a ofrecer aperturas a los modos de relato que nos dan cuenta tanto de nuestra cotidiana intimidad creativa como de los códigos actuales que la hacen pública, haciendo historias (stories) del personal modo de proceso previo de cada historia publicada.

\section{ABSTRACT.}

The present communication comes to show an artistic project based on reconfiguring, by crossing, two types of codes, one of mass consumption such as the comic, and another of the specialized and face-to-face reception such as painting. Likewise, the theme that, as we shall see, is the subject of narrativization through the aforementioned disciplinary confluence, brings back the result of the public dissemination of intellectual work to the context of its purely domestic procedural conditions. Therefore, through the interested conjugation of these disciplines, I produce a sort of spatial narratives that come to modify the modes of reception of the cultural objects to which they refer (novels, exhibitions, articles, essays, etc.). To this end, a whole work program has been developed that delves into the possibilities of pictorial representation to generate metarrelates, producing a series of installations that, based on transforming the exhibition 
space into an infinite succession of large vignettes, integrate paintings that They attend to the graphic and argumental characterization of the own disorder of the intimate practices of room during the work, that comes to be revealing of settlements in the domestic territory given by its condition of spaces to create histories, since all they are places of life and Work of different professional narrators. Each painting-vignette, therefore, is titled with the one of the description sheet of work that each one of these authors was realizing when receiving the visit - camera in hand - of whom it subscribes, from whose photographs the paintings have been composed, narrations Of second degree that come to offer openings to the modes of storytelling that give us account both of our daily creative intimacy and of the current codes that make it public, making stories of the personal way of previous process of each published history.

\section{CONTENIDO.}

\section{INTRODUCCIÓN.}

Stories from homes es una obra que hace del tiempo campo de trabajo privilegiado, desde unas estrategias representacionales que habitan los recursos de la ficción, además de en su sentido literal, en distintas variables derivadas: metaficción, paraficción y heteronomías. Sin embargo, tales figuras que articulan el plano general del proyecto en el que se inscribe esta obra, dejarán lugar en las líneas que siguen a una reflexión mucho más específica sobre los usos que, a través de ellas, me han permitido configurar una propuesta de recuperación de la duración individual. Por tanto, será de diferentes temporalidades, dependientes de la conjugación de los distintos elementos que entran en juego en este trabajo, de lo que trate a continuación. Multitemporalidad, alternacia de ritmos, velocidades y densidades de tiempo, remisión y heterocronía serán algunos de los conceptos que me permitirán desgranar el sentido político del empleo que en Stories from homes se hace de la pintura, del cómic y del espacio. Un sentido que es un interés político porque lo que planteo se enraíza en la voluntad de indagar en las posibilidades de recuperación del tiempo individual en un presente, el nuestro, definido por sus múltiples medios y modos de virtualizarnos los años, meses, semanas, días, horas y minutos en un devenir existencial que asumimos como naturaleza comunicacional inalterable y que, aquí, propongo repensar mediante el arte.

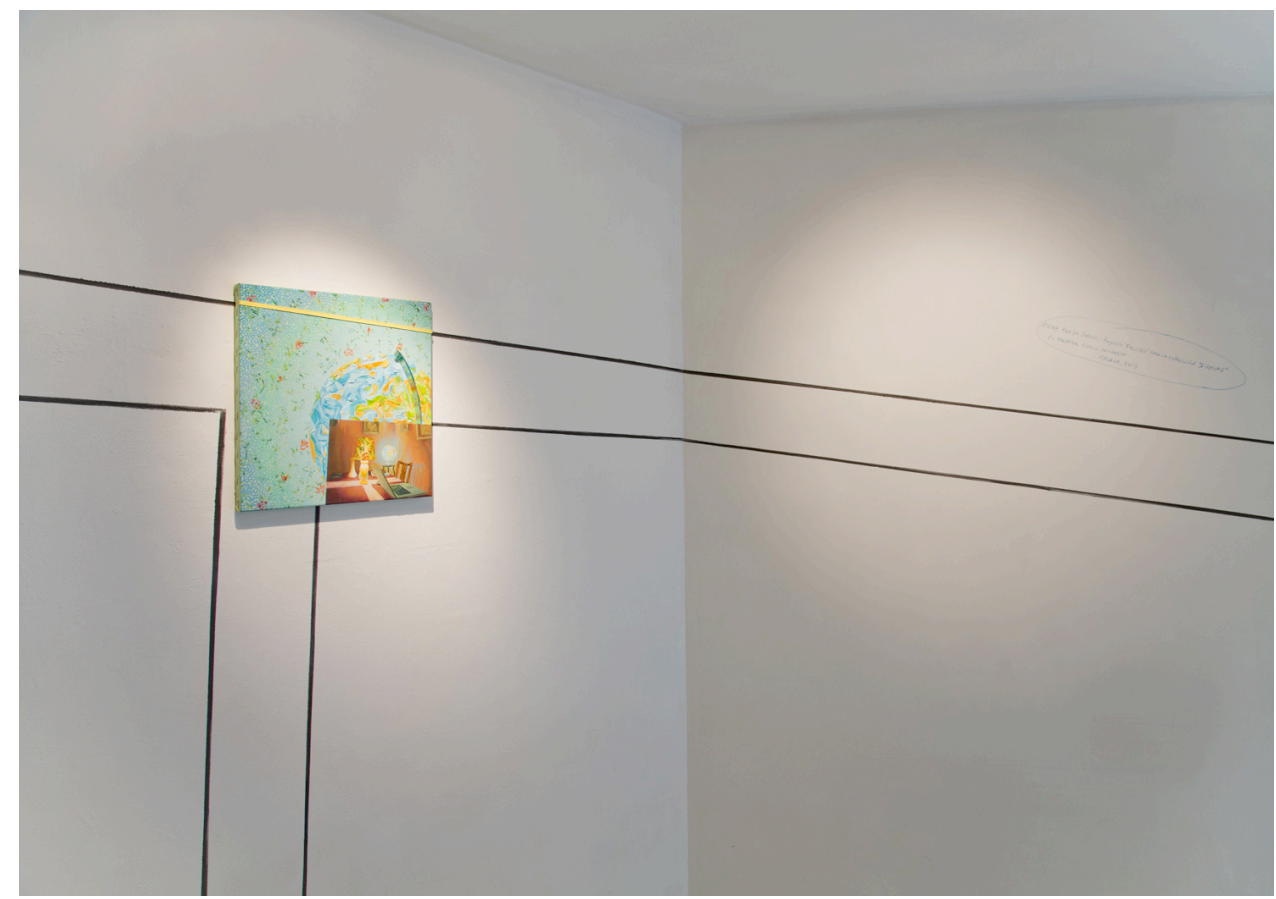

Ilustración 1. Carlos Miranda. Stories from homes, Galería JM, Málaga, 2014-15. Vista general de Erika Pardo Sköug. Proyecto "Faluröd" para la exposición "Sirenas". El Palmeral Espacio Iniciarte. Málaga, 2014. 


\section{DESARROLLO.}

"Vivir... en tiempo real, aquí y ahora". Así es introducido uno de los ítems temáticos que articulan este congreso, el enunciado como "Dónde y cuándo". No puedo negar que, cuando me interesé por participar en el encuentro y leí esto, me sentí directamente impelido por la especie de desafío que me estaban lanzando tales palabras. Mi trabajo de investigación artística, especialmente concernido por las cuestiones narrativas, viene desde hace ya bastante profundizando en las potencias de temporalidad que puede desarrollar la representación con imágenes "fijas": fotografía, escultura, pintura, instalación, etc. Por tanto, se entiende que esos "aquí y "ahora", que ese "tiempo real", me resultasen provocadores desde la perspectiva de unos modos de comprensión del acto de representar que, precisamente, hallan su sentido en la movilidad y labilidad de la significancia de tales términos. Especialmente en nuestros días -y entiendo que éste es uno de los objetivos del congreso que nos reúne- es necesaria una actualización de los análisis que a ellos se refieren, $\mathrm{y}$ a esto atiendo, entre otras cuestiones, desde el proyecto artístico que aquí traigo.

En una época, la actual, en la que, efectivamente, hemos de aprender a resituar nuestra condición de sujetos como habitantes de la velocidad comunicacional, es más, de su aceleración multifocal, el problema de cómo conceptualizar los nuevos modos de vida que esto implica no puede dejar de ser objeto del arte. Especialmente hay un aspecto, el de la propiedad y modalidades del tiempo, que es tratado con asiduidad en razón de la situación de emergencia que hoy manifiesta en todos los ámbitos de la existencia. Hace ya más de treinta años, antes de internet, que podemos, con Jonathan Crary (2015), reconocer la situación: “[...] con la contrarrevolución de los años ochenta, el auge del neoliberalismo, la comercialización de los ordenadores personales y el desmantelamiento de los sistemas de protección social, el asalto a la vida cotidiana adquiere una nueva ferocidad. El tiempo mismo se mercantilizó y el individuo se redefinió como agente económico a tiempo completo, incluso en el contexto del (capitalismo sin trabajo `" ${ }^{1}$. En efecto, esta diagnosis no ha de ser obviada por un arte que se haga cargo de su presente. De hecho, no lo es, y las producciones que a ello se aplican son tan numerosas como, en muchos casos, excelentes en su operatividad reveladora. Las poéticas de la imagen-movimiento que hoy podemos disfrutar han hecho del problema de la multitemporalidad y su posesión un campo central de trabajo que, por suerte y por necesidad, nos sorprende sin pausa. Sin embargo, ya he adelantado que será desde la imagen fija que me ubique con mi obra en estos problemas, entre otras razones porque me parece particularmente interesante que ese "asalto a la vida cotidiana" que nos hace notar Crary sea tratado desde parámetros propios de la misma, de forma que no sólo los medios y dispositivos tecnológicos que canalizan la sociedad de la comunicación y de la hiperconexión (vídeo, redes, móviles, etc.), profundamente vinculados a la imagen-movimiento, sean aptos para ocuparse, desde la producción artística, de esos aspectos de las condiciones civilizatorias que nos ha tocado vivir, pues mantenemos hoy perfectamente hábiles estructuras comunicacionales, epistemológicas y culturales que sostienen unos modos de relación -por cierto muy relacionados con ciertos usos y percepciones de lo que Bergson llamase la duración- que entiendo pueden revelar aspectos principales, si bien poco mediáticos, del cambio civilizatorio en el que estamos inmersos. Quiero recordar aquí, por ejemplo, la tremenda carga política que en esta línea desplegaba el monumento satírico que, anticipándose al respecto, nos regalara, ya en años cincuenta, Jacques Tati (1958) con su obra Mi tío ${ }^{2}$, en la que recurría a situar el tiempo lento preconsumista como resistencia de un humanismo que se contrapone, por coexistencia, a los nuevos modos de vida y construcción de identidad espectacularizada arbitradas por las modas (tecnológicas, de diseño, etc.). Estos ámbitos de trabajo que valoran la reivindicación del tiempo individual, si por algo se caracterizan a día de hoy, es por reconocer las raíces de sus cualidades en la arqueología del presente, es decir, por ubicarse en el cuestionamiento radical de los relatos que nos cuentan lo que somos. Por eso atiendo, con la investigación artística que aquí traigo, a una ya "antigua" cultura de masas que incorpora la narración, como es el cómic, para cruzarla con otra mucho más "antigua" aún pero bastante menos masiva como es la pintura. Porque en los cruces de disciplinas que vienen desde atrás en la historia encuentro una sofisticación reconfiguradora de éstas que muestra procesos de cambio que, de otro modo, no podrían ser tan genealógicamente específicos ni reveladores.

Por tanto, partamos de la imagen fija... O, al menos, desde la imagen de apariencia fija: es bien certera, por actual, aquella anotación de Aby Warburg (1888-1905) de que "para atribuir movimiento a una figura que no se mueve es necesario despertar una serie de imágenes que se encadenan unas con otras -no una imagen aislada: pérdida de la contemplación tranquila”" Y no se refería el historiador alemán a un encadenamiento como sucesión de más imágenes ${ }^{4}$, sino a que esa figura única remitiese a otras figuras, no

\footnotetext{
${ }^{1}$ CRARY, J. 2015. 24/7. El capitalismo al asalto del sueño. Barcelona: Ariel, p. 79. (La cursiva es mía).

${ }^{2}$ TATI, J. 1958. Mi tío (Mon oncle). Francia, Italia: Continental.

${ }^{3}$ WARBURG, A. 1888-1905: Fragmentos para los fundamentos de una psicología monista del arte. Londres: Warburg Institute Archive, III, 43.1-2.. Cit. en DIDI-HUBERMAN, G. 2009. La imagen superviviente. Historia del Arte y tiempo de los fantasmas según Aby Warburg. Madrid: Abada, p. 439.

${ }^{4}$ Gilles Deleuze hizo notar, precisamente, cómo "la duración bergsoniana no se define tanto por la sucesión cuanto por la coexistencia". Cit. en BAL, M. 2016. El tiempo que se toma. Contranarrativas. Revista de Estudios Visuales, n 0 . Murcia: Proyecto de Investigación "El Espacio Articulado: Contextualizaciones en el arte contemporáneo, espacialidades y temporalidades en la producción artística actual" HAR2015-64106-P (MINECO/FEDER). Universidad de Murcia. Disponible en: http://www.um.es/artlab/index.php/revista/the-timeit-takes-el-tiempo-que-tarda/ Llama la atención la coincidencia epocal entre los textos donde Bergson compone su idea de duración (Materia y memoria, 1896) y Warburg articula la base de la distinción citada entre encadenamiento y sucesión ("Fragmentos para los fundamentos de una psicología monista del arte”, 1888-1905). Desde perspectivas e intereses muy diferentes, hace más de un siglo, el tiempo ya era reconsiderado por ambos mucho más allá de su abstracción positivista para situarlo en el ámbito de la percepción individual. De ahí la actualidad de ambos: nuestros días nos exigen recuperar esa individuación íntima del mismo que una vez nos definiese como sujetos.
} 
presentes sino evocadas, que surgen de la memoria, de la historia, de la cultura. Habla de relaciones con el pasado que permitan mover, hacer temblar las seguridades necesarias para tal contemplación tranquila. Si "las imágenes portadoras de supervivencias no son otra cosa que montajes de significaciones y temporalidades heterogéneas" ${ }^{5}-\mathrm{y}$ entendiendo esa supervivencia por lo que, apartado del relato oficial, late por debajo como periódica aparición no deseada por éste-, la utilidad hoy de tal planteamiento es que nos permite reconocer cómo el acto de diferir significación desde una imagen (un cuadro, una fotografía, un objeto, etc.) a otro plano ausente de su presencia como cosa, constituye una estrategia de representación especialmente reveladora de las maneras por las que nuestro presente nos permite relacionarnos con el mundo. Unas maneras que establecen, ante todo, vías de desplazamiento de sentido, de tiempo y de espacio. Por eso, como veremos, nuestro "tiempo real", nuestros "aquí" y "ahora" son tan estables como el color de un camaleón. Porque dependen fundamentalmente de la relación que establezcan con los contextos en los que, en cada momento, funcionen como unidades de sentido. Por eso veremos cómo se mueven las imágenes fijas de las que hablaré a continuación.

"Diferir", que es derivado del latín fĕrre, 'llevar', es un término profundamente temporal. Implica una extensión, una dilatación del tiempo (aplazar, retardar, retrasar, hacer algo en otro momento...) y también conlleva una cualidad de diverso, de heterogéneo: de diferencia $^{6}$. Remitir a otra cosa es diferir un sentido hacia algo ausente, que adquiere presencia por esta acción. Es operar un desplazamiento desde un tiempo real a uno "fantasmagórico", precisamente el del tipo de re-presentación que aquí me interesa, que es la que emplea el tiempo de la metaficción. Porque en ese parámetro se ubican las estrategias discursivas de Stories from homes, el proyecto que vengo a presentar como modo de multitemporalidad desde, como digo, la imagen fija. Este trabajo, en curso desde 2012, ha sido objeto, a lo largo de su desarrollo, de tres exposiciones individuales ${ }^{7}$ y de varias participaciones en exhibiciones temáticas o colectivas, y es en su condición instalativa en exposición donde se funda la plenitud de sus potencias de trabajo con el tiempo. Así, la obra está articulada como una especie de sinfonía de heterocronías que continuamente conjugan diversos planos temporales en el mismo espacio. Para ello, me he servido de tres elementos básicos: una serie de pinturas, un modo de intervención directa sobre las paredes blancas a base de grandes viñetas de vinilo negro, y el propio espacio de la sala expositiva.

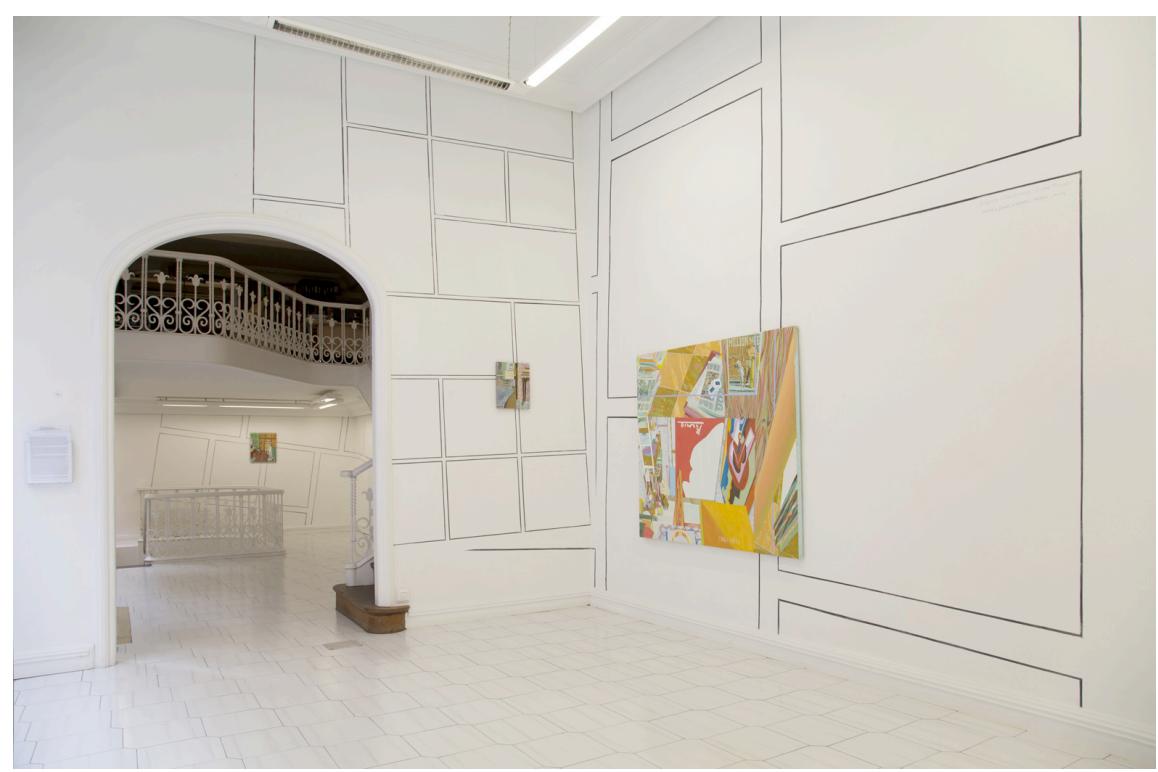

Ilustración 2. Carlos Miranda. Stories from homes, Galería JM, Málaga, 2014-15. Vista general de Rogelio López Cuenca. "Ciudad Picasso". Galería Juana de Aizpuru. Madrid, 2011. (1) y (3).

Comencemos por los cuadros. Cada uno de ellos es una técnica mixta (acrílico y óleo) sobre tela que figurativamente despliega, a su vez, varios momentos del mismo espacio desde distintos puntos de vista. Tales representaciones de interiores (asimilables a la tradición barroca de la pintura de género) atienden a la caracterización gráfica y argumental del desorden propio que generan distintos narradores (novelistas, comisarios, artistas, ensayistas, críticos, etc.) con sus prácticas íntimas de habitación durante el trabajo, pues todos desarrollan su labor en casa. Esto es, las pinturas se interesan por cómo ese desorden espacial viene dado por los

\footnotetext{
${ }^{5}$ DIDI-HUBERMAN, G. op. cit., p. 438.

${ }^{6}$ Víd. COROMINAS, J.; PASCUAL, J. A. 2012. Diccionario crítico etimológico castellano e hispánico. Madrid: Gredos; y también MOLINER, M. 2001. Diccionario de uso del español. Madrid: Gredos.

${ }^{7}$ El proyecto The Estate of Anonymous (VII): Stories from homes ha sido mostrado en sucesivos capítulos de su desarrollo en la Galería JM (Málaga, 2014-15), en el Espacio El Butrón (Sevilla, 2013) y en el Centro d’Arte Piana dei Colli (Palermo, IT, 2012). Víd. www.carlosmiranda.eu
} 
muy personales modos de habitación que se producen durante el proceso de componer el orden de sus relatos. Y son precisamente las fichas documentales de esos relatos los que dan título a cada pintura: he ahí la primera operación de remisión de sentido a otra cosa de la que se da a contemplar. Cuando vemos, por ejemplo, una de las pinturas dedicadas al espacio doméstico de Rogelio López Cuenca durante el proceso de producción de su proyecto Ciudad Picasso, y atendemos al rótulo que lo identifica en la pared, leemos "Rogelio López Cuenca. Ciudad Picasso. Galería Juana de Aizpuru. Madrid, 2011". No es la ficha técnica del cuadro presente, sino la de la obra en la que se difiere. Y esto se establece, además, mediante un bucle entre el tiempo privado del proceso de construcción de relatos y el tiempo público de su difusión -su publicación- como productos culturales. Mas sumemos ahora otro plano de temporalidad: como meros objetos pictóricos, aparte del ya citado recurso de simultanear dos puntos de vista en la misma pieza, los cuadros -y por eso son cuadros y no, por ejemplo, fotografías- ostentan el propio tiempo de la pintura, la cual es pretendidamente, si se me permite la expresión, acontecimental. Pues no son imágenes sino pinturas, esto es, revisten su condición presencial en primer término. El profesor Daniel Arasse (2008) lo explicaba muy acertadamente del siguiente modo:

Esta presencia de la obra [surge] de una desviación de la representación dentro de la propia representación, una desviación que resulta imposible reconducir a la coherencia unitaria de un enunciado de la imagen. Para que esa presencia inscrita en la obra adquiera presencia frente a quien la mira, es preciso el tiempo de la mirada, su recorrido, su paseo, y el ritmo que se trama en ellos de un instante a otro, de acontecimiento en acontecimiento. ${ }^{8}$

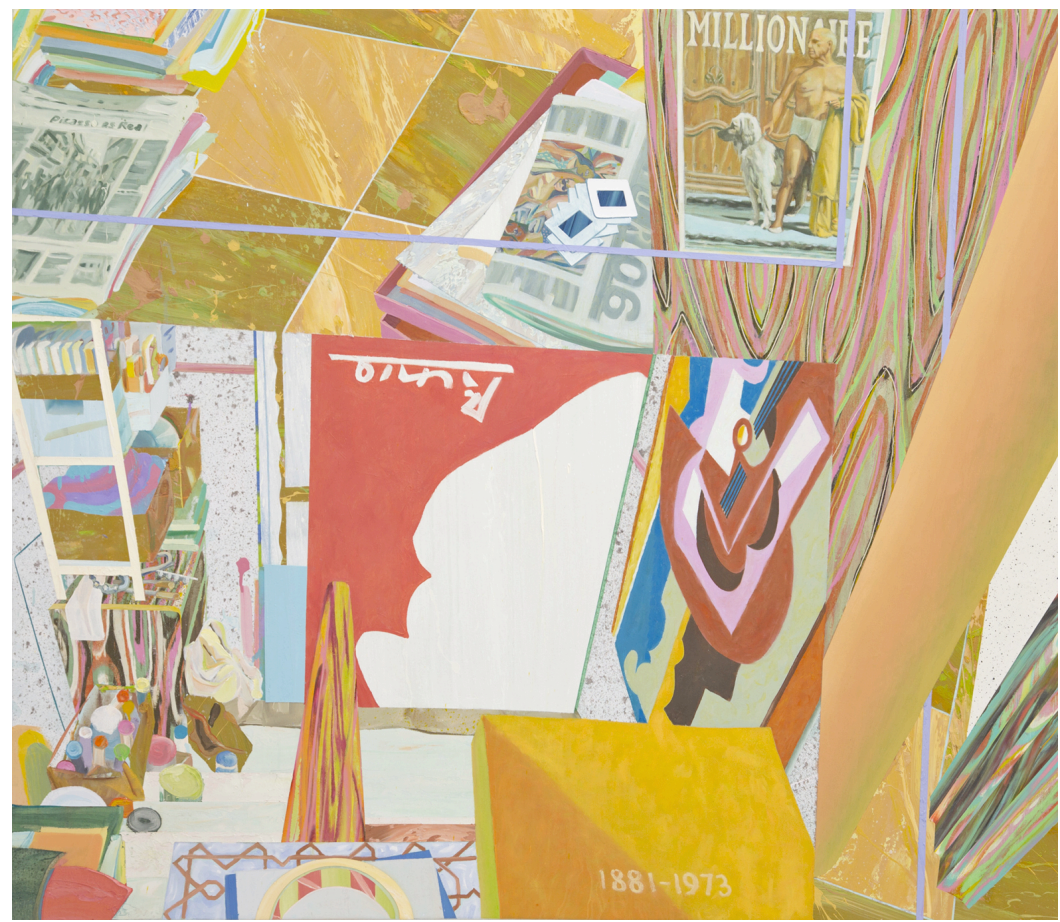

Ilustración 3. Carlos Miranda. Rogelio López Cuenca. "Ciudad Picasso". Galería Juana de Aizpuru. Madrid, 2011. (3). Acrílico y óleo sobre lienzo. 131 x $150 \mathrm{~cm} .2014$.

El concepto de acontecimiento en pintura es básico en el discurso que nos ocupa, pues uno de los planteamientos de este trabajo con el tiempo es su demora, incluso su suspensión al implicar la tradicional -y también tan vituperada- idea de contemplación. El propio Arasse se vale en un momento dado de las palabras del ensayista y crítico de arte francés Gaëtan Picon (1970) para traernos la idea: "La temporalidad llega a su colmo en esas imágenes en las que vemos menos la imagen de lo que sentimos la pincelada [...], la imagen no es más que una imagen del gesto" ${ }^{\prime 9}$. El sentido de incidir tan especialmente en la cualidad pictórica de los cuadros -aparte del mero placer de hacerlos así- es establecer un contrapunto de intensidades y velocidades en esta superposición de tiempos distintos. Así, para seguir avanzando en este recorrido entre tiempos unos y otros, toca ahora hablar de otro elemento más, uno que configura, y reconfigura, cada cuadro. Me refiero a las viñetas que forman parte de estas composiciones. Son ellas las que indican la pertenencia de cada pintura a una supuesta sucesión propia de la narración gráfica, a su particular modo de establecer temporalidad: la de la lectura secuencial, que implica una narración lineal. Y, al tiempo, son las que inscriben los cuadros, como fragmentos visibles, en las grandes páginas de cómic que son las paredes de la sala. Por eso reconfiguran las pinturas: de su unicidad como presencias los llevan a

\footnotetext{
${ }^{8}$ ARASSE, D. 2008. El detalle. Para una historia cercana de la pintura. Madrid: Abada, p. 239.

${ }^{9}$ PICON, G. 1970. Admirable Tremblement du temps. Ginebra: Skira, p. 99. Cit. en ARASSE, D. op. cit., p. 238.
} 
su condición de trozos de una historia evocada por las innumerables viñetas blancas del muro. Esta generación de un continuo ir y venir de la temporalidad espacializada de la lectura (cómic) a la dilatada de la contemplación (pintura) es potenciada, asimismo, por el citado fundamento instalativo de la obra, que me permite articular un duración, un tiempo inmersivo, no lineal sino experiencial, que viene dado por el recorrido físico del espectador por esos espacios totalmente "viñeteados".

\section{CONCLUSIONES.}

Un gran pintor, especial y muy escépticamente interesado en las paradojas de cómo nos cuentan y nos contamos el mundo, Chema Cobo (1999), dice que "es la tristeza la que da cuerda a los relojes" ${ }^{10}$. La tiranía positivista del tiempo del reloj se nos aparece hoy como la dependencia de su aceleración, dada por una hiperconexión que no podemos dejar de atender sin menoscabar la ilusión de nuestra identidad social e informada. En efecto, como explica Mieke Bal (2016), "debido a que funcionamos muy a menudo en modo multitarea, también nos encontramos multi-temporalizados: viviendo simultáneamente ritmos diferentes en un mismo tramo de tiempo" ${ }^{11}$.

A esta experiencia de multiplicación de ritmos, Bal (2016) la llama heterocronía ${ }^{12}$. Y desde el planteamiento representacional aquí expuesto, he querido llevar tal concepto a la que reconozco como su capacidad liberadora, pues en las instalaciones pictóricas que propongo esa multiplicidad quiere tornarse duración, tiempo devuelto a la posesión del individuo, a modo de una sinfonía en efecto heterocrónica que le permita fluir en el transcurso de su devenir por las remisiones de la obra: retomar el tiempo haciendo tiempos.

\section{FUENTES REFERENCIALES.}

ARASSE, D. 2008. El detalle. Para una historia cercana de la pintura. Madrid: Abada.

BAL, M. 2016. El tiempo que se toma. Contranarrativas. Revista de Estudios Visuales, no 0. Murcia: Proyecto de Investigación "El Espacio Articulado: Contextualizaciones en el arte contemporáneo, espacialidades y temporalidades en la producción artística actual" HAR2015-64106-P (MINECO/FEDER). Universidad de Murcia. [Consulta 19/03/2017] Disponible en: http://www.um.es/artlab/index.php/revista/the-time-it-takes-el-tiempo-que-tarda/

COBO, CH. 1999. Amnesia. Cáceres: Galería Bores\&Mallo.

COROMINAS, J.; PASCUAL, J. A. 2012. Diccionario crítico etimológico castellano e hispánico. Madrid: Gredos.

CRARY, J. 2015. 24/7. El capitalismo al asalto del sueño. Barcelona: Ariel.

DIDI-HUBERMAN, G. 2009. La imagen superviviente. Historia del Arte y tiempo de los fantasmas según Aby Warburg. Madrid: Abada.

MIRANDA, C. 1999-2016. The Estate of Anonymous (traducción VII): Stories from homes. [Consulta 20/03/2017] Disponible en: www.carlosmiranda.eu

MOLINER, M. 2001. Diccionario de uso del español. Madrid: Gredos.

PICON, G. 1970. Admirable Tremblement du temps. Ginebra: Skira.

TATI, J. 1958. Mi tío (Mon oncle). Francia, Italia: Continental.

WARBURG, A. 1888-1905: Fragmentos para los fundamentos de una psicología monista del arte. Londres: Warburg Institute Archive, III, 43.1-2

\footnotetext{
${ }^{10} \mathrm{COBO}, \mathrm{CH} .1999$. Amnesia. Cáceres: Galería Bores\&Mallo, p. 48.

${ }_{11}^{11}$ BAL, M., op. cit.

12 Íbid.
} 